\title{
A "nova" Ciência da Informação em Revista: identidade visual, distinção e visibilidade
}

Este número de 2019 da Ciência da Informação em Revista é lançado com muita satisfação pela Equipe Editorial por ser o 16 fascículo publicado em seus seis anos de existência e por marcar algumas mudanças e novos desafios para o periódico. Uma das primeiras mudanças a ser destacada é a criação e o lançamento da nova identidade visual da revista, construída com a cooperação dos editores e desenvolvida por Raphael Freitas Souza, Designer de Produto pela Universidade do Estado de Minas Gerais (UEMG) e mestrando em Design na Universidade Federal de Pernambuco (UFPE). A nova identidade (Figura 1), elaborada por meio da metodologia TXM Branding, carrega principalmente a reflexão, os diálogos revistos na experimentação científica e a fluidez informacional em curso constante.

Figura 1 - Conceito da nova identidade visual da Ciência da Informação em Revista

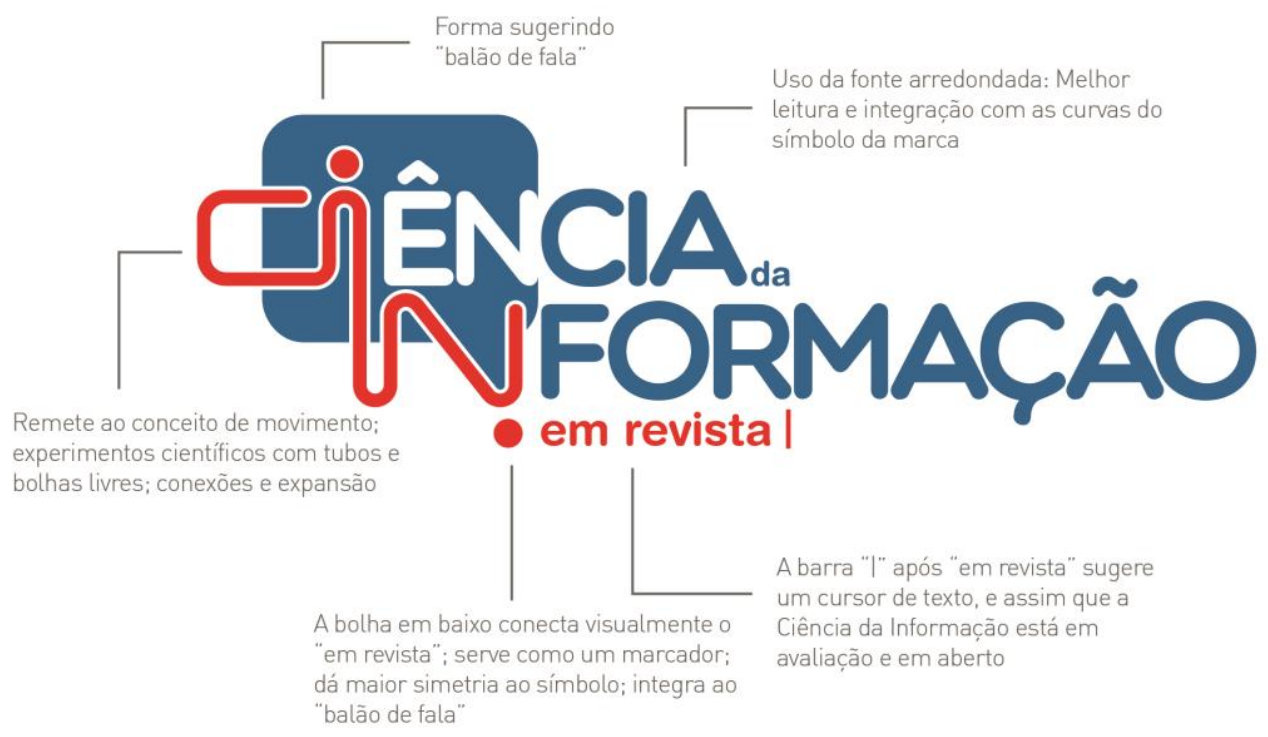

Outra mudança está relacionada à adesão aos padrões internacionais de identificação e distinção de autoria e de objetos como os identificadores Open Researcher and Contributor ID (ORCiD) para autores, que passa a ser obrigatório como item nos metadados da submissão, e o Digital Object Identifier (DOI) para os artigos, que passam a ser incluídos no sistema da revista. Ambos indicadores aparecem na primeira página do artigo que conta com outras informações como datas em que o artigo foi recebido, aceito e publicado, indicação da Licença Creative Commons 4.0 International praticada pela revista e layout com coluna única que favorece a leitura em dispositivos readers.

A última mudança se coloca como um desafio aceito pela Ciência da Informação em Revista no que se refere ao marketing científico digital e à gestão da presença online do periódico nas mídias sociais com vistas ao engajamento, à visibilidade e ao posicionamento. Em

DOI: $10.28998 /$ cirev.2019v6n1ed

Este editorial foi publicado sob uma Licença Creative Commons 4.0 
parceria com a Alexandria Agência de Marketing Digital ${ }^{1}$, responsável pelo plano de ação do periódico, foram definidas as mídias sociais de engajamento, reconhecidas como aquelas na qual a "marca" vai até o consumidor. Nesse tipo de mídia, conteúdo tem "prazo de validade" e não é otimizado nos buscadores, o que exige produção de conteúdo semanal, cuja grande métrica é o relacionamento. Nesse quesito foram escolhidas o Facebook e o Instagram.

No Facebook ${ }^{2}$, criamos um card base para compartilhar todos os novos artigos destacando na imagem o título do artigo, o(s) nome(s) do(s) autor(es) e a categoria. A legenda/descrição da publicação será feita com base no resumo do artigo acompanhada do link direto para o mesmo. No Instagram ${ }^{3}$, o card e a legenda utilizada serão os mesmos veiculados no Facebook, porém, com o acréscimo das palavras-chaves do artigo como hashtags. Para ambas as mídias, a partir do lançamento desta edição, teremos uma postagem por dia, no horário de maior fluxo de usuários ativos (seguidores da página). Seguiremos com postagens diárias até que sejam veiculados todos os artigos da edição. Em seguida, diminuiremos a frequência para duas publicações semanais utilizando os artigos das edições anteriores.

No quesito de mídias sociais de posicionamento, são consideradas as mídias nas quais o consumidor vai até a marca a partir de buscas (Google, Bing, etc). Aqui entra conteúdo duradouro produzido sobre palavras-chave e a produção de conteúdo é pontual tendo como grande métrica a visibilidade. Foram escolhidas o Pinterest $^{4}$ e o Slideshare ${ }^{5}$. De maneira geral, ambas as mídias sociais serão usadas para veicular infográficos produzidos internamente com base em artigos-chave da revista com inclusão de link de acesso ao artigo, descrição do seu resumo e uso de hashtags com frequência de publicação semanal.

O presente número da Ciência da Informação em Revista traz um conjunto de 11 (onze) artigos, sendo dois artigos originais e nove relatos de pesquisa. No primeiro artigo original, "Em torno da mediação: contribuições para fundamentação teórico-epistemológica da categoria nos estudos da informação", a autora Ana Amélia Lage Martins analisa a gênese dialética da categoria mediação, destacando as contribuições trazidas pelos trabalhos de Manuel Martin-Serrano e César Bolaño na construção e compreensão dos objetos informacionais. No segundo artigo original, "Semiótica, música e organização do conhecimento: contribuindo para o debate", os autores Jozuel Vitorino de Moura e Carlos Cândido de Almeida analisam o potencial informativo do campo da música sob a perspectiva da semiótica de Charles Sanders Peirce. Para os autores, a música apresenta significados subjetivos que estão relacionados ao contexto social e às experiências humanas já vivenciadas, sendo possível compreender que as informações musicais estão intimamente relacionadas ao contexto no qual o sujeito está inserido, pois é nele que, por meio do processo cognitivo, se constrói o conhecimento.

No primeiro relato de pesquisa "Desinformação e competência em informação: discussões e possibilidades na Arquivologia", as autoras Ana Roberta Pinheiro Moura, Renata Lira Furtado e Regina Célia Baptista Belluzzo mapearam as possíveis interseções entre o fenômeno Desinformação, a temática Competência em Informação e a Arquivologia no cenário nacional. Segundo as autoras, os preceitos da Competência em Informação configuramse como uma possibilidade tanto de combate, como de redução da desinformação na sociedade e no contexto arquivístico, sendo que a disseminação e a preservação de Fake News

\footnotetext{
${ }^{1}$ Alexandria Agência de Marketing Digital: http://alexandria.marketing.

${ }^{2}$ Ciência da Informação em Revista no Facebook: https://www.facebook.com/ciemrevista.

${ }^{3}$ Ciência da Informação em Revista no Instagram: https://www.instagram.com/ciemrevista.

${ }^{4}$ Ciência da Informação em Revista no Pinterest: https://br.pinterest.com/ciemrevista.

${ }^{5}$ Ciência da Informação em Revista no SlideShare: https://pt.slideshare.net/ciemrevista.
} 
bem como de outras formas de desinformação poderão acarretar danos irreparáveis para a sociedade futura. No segundo relato, "Capital informacional das comunidades sociais virtuais como suporte a gestão de MPE's", os autores Mônica Ribeiro Gama e Carlos Cesar Santos verificam como as MPE's de Rondon do Pará utilizam o capital informacional existente nas comunidades virtuais na gestão de seus empreendimentos. O estudo constatou que as empreendedoras remodelam seus empreendimentos conforme informações coletadas nas comunidades virtuais traçando o perfil de suas clientes para direcionar à comunicação conforme os gostos e desejos da consumidora agregando valor ao seu negócio. No terceiro relato, "Indexação de xilogravuras de cordel: uma abordagem sob a perspectiva cognitiva", as autoras Raimunda Fernanda dos Santos, Maria Elizabeth Baltar Carneiro de Albuquerque e Dulce Amélia de Brito Neves investigam os aspectos cognitivos inerentes à atividade de indexação de xilogravuras de capas de folhetos de cordel efetuada por Bibliotecários.

No quarto relato, "Web semântica em repositórios: ontologia para representação de bibliotecas digitais", os autores Marcel Ferrante Silva, Dalton Lopes Martins e Joyce Siqueira propõem um modelo conceitual de ontologia voltada à representação de conteúdo semântico em repositórios digitais visando aprimorar os processos, principalmente, para recuperação de dados na web, possibilitando ao usuário melhores resultados em suas buscas. No quinto relato, "Bibliotecas como makerspace: oportunidades de implementação a partir de um caso prático", as autoras Rocelle Gil Santos e Ana Clara Cândido analisam as ações utilizadas na implementação de makerspace em bibliotecas na prática como subsídio para a proposta de um guia preliminar para futuras implementações. No sexto relato, "Biblioteca híbrida: o $Q R$ Code e o movimento booktuber como recursos de promoção da literatura", o autor Carlos Robson Souza da Silva propõe uma estratégia de hibridização de bibliotecas, utilizando-se da ferramenta QR e sugerindo o uso desta para criação de elos entre o mundo literário físico e sua manifestação virtual, como meio de incentivo à leitura, por intermédio do uso de estratégias de marketing em mídias digitais.

No sétimo relato, "Perfil do público-visitante dos museus disponíveis no site 'Era Virtual'", os autores Cesar Eugenio Macedo de Almeida Martins e Renata Maria Abrantes Porto Baracho analisam o perfil e as características dos usuários dos museus virtuais disponíveis no site "Era Virtual" para compreensão das demandas e necessidades desse público. No oitavo relato, "Biblioterapia: análise dos artigos indexados na Base de Dados em Ciência da Informação (BRAPCI)", as autoras Jéssica da Silva Gadelha e Gabrielle Francinne de S. C. Tanus analisam as publicações sobre a biblioterapia indexadas na BRAPCl, descrevendo-as pelas variáveis autor, periódico e ano de publicação, a fim de explorar como esse campo de estudo e de prática vem se comportando no decorrer dos anos. Por fim, no oitavo no relato, "Prevenção de desastres socioambientais no Estado de Santa Catarina: levantamento bibliográfico das universidades do Estado", os autores Fabio Guimarães Vazquez e Ursula Blattmann investigam os estudos acadêmicos da Universidade do Estado de Santa Catarina, da Universidade Federal de Santa Catarina e da Universidade do Sul de Santa Catarina sobre o tema prevenção de desastres socioambientais em Proteção e Defesa Civil.

A Ciência da Informação em Revista agradece aos autores pela produção dos artigos e aos avaliadores pela análise e emissão dos respectivos pareceres. Deseja, enfim a todos, uma boa leitura.

\section{Edivanio Duarte de Souza}

Ronaldo Ferreira de Araujo

Editores 